\title{
A Multilevel Converter-Based Universal Power Conditioner
}

\author{
Leon M. Tolbert, Fang Z. Peng \\ Oak Ridge National Laboratory \\ P.O. Box 2009, Bldg. 9102-1 \\ Oak Ridge, TN 37831-8038 \\ Tel: (865) 576-6206 \\ Fax: (865) 241-6124 \\ E-mail: tolbertlm@ornl.gov \\ E-mail: pengfz@ornl.gov
}

\author{
Thomas G. Habetler \\ Georgia Institute of Technology \\ School of Electrical and Computer Engineering \\ Atlanta, GA 30332-0250 \\ Tel: (404) 894-9829 \\ Fax: (404) 894-4641 \\ E-mail: tom.habetler@ece.gatech.edu
}

\begin{abstract}
This paper presents the development of a control scheme for a multilevel diode-clamped converter connected in a series-parallel fashion to the electrical system such that it can compensate for deviations in utility voltage and act as a harmonic and/or reactive current source for a load. Simulation results are given for the real-time control scheme when applied to a 5-level converter for different combinations of the following power conditioning objectives: sag compensation, voltage balancing, current harmonic compensation, and reactive power compensation. Level usage in the series inverter and parallel inverter is analyzed for the different compensation objectives, and a method to maximize level usage at low modulation indices is highlighted.
\end{abstract}

\section{INTRODUCTION}

Deregulation of the power industry will undoubtedly have a large impact on utilities' competition for customers. Many industrial and commercial customers that cannot tolerate variations in their electrical supply will request "premium power" with specifications restricting certain tolerances in a utility's voltage magnitude, distortion, and limits on the number of outages per year. Utilities, in turn, will put limitations on the power factor, current harmonic distortion, and peak power that the customer can impose on the utility. To meet the objectives detailed in these new premium power agreements, the implementation of advanced power electronic technologies that can simultaneously improve the power quality for both utilities and their customers will be in demand.

By connecting two active inverter-based filters with a common dc link, the combined back-to-back converter can be interfaced with the utility system in both a series and parallel manner. By having these two inverters connected to the electrical system, simultaneous control of the current

Prepared by the Oak Ridge National Laboratory, Oak Ridge, Tennessee 378318038, managed by Lockheed Martin Energy Research, Corp. for the U.S. Department of Energy under contract DE-AC05-96OR22464. A contractor of the U.S. Government has authored the submitted manuscript. Accordingly, the U.S. Government retains a nonexclusive, royalty-free license to publish or reproduce the published form of this contribution, or allow others to do so, for U.S. Government purposes. demanded from the utility and the voltage delivered to the load can be accomplished. This series-parallel active power filter has been referred to as a universal power conditioner [1-3] when applied to electrical distribution systems, and as a universal power flow controller when applied at the transmission level [4-6].

Multilevel voltage source inverters' unique structure allows them to span high voltages and to reduce individual device switching frequency without the use of transformers. The diode-clamped inverter can synthesize a desired waveform from several levels of dc voltages, and all six phases of a back-to-back converter can share the same common dc link [7]. Consequently, the integration of a multilevel diodeclamped inverter into a universal power conditioner is an enticing prospect.

A multilevel universal power conditioner (MUPC) offers many options when deciding what type of control should be used in the compensation of source voltages and load currents. The objectives of the compensation (voltage sag, unbalanced voltages, voltage harmonics, current harmonics, or reactive power) also play an important role in the control of the two back-to-back inverters.

For a multilevel power conditioner that will perform sag compensation, the majority of its operating mode will likely be in low modulation index operating regions because sags are quite infrequent and for a minimal duration. Because of this, how to maximize level usage in a diode-clamped inverter for low modulation indices has been previously explored [11]. A procedure has been developed that enables the inverter to switch at higher frequencies during low modulation indices. This increases the frequency spectrum and hastens the dynamic response of the inverter, yet does not exceed the allowable switching loss of the active devices.

Because of the different compensation objectives of the series inverter and the parallel inverter, two distinct control techniques are adapted for their use. Simulation results verify that the algorithms developed will enable the back-to-back diode-clamped converter to function as a universal power conditioner. 


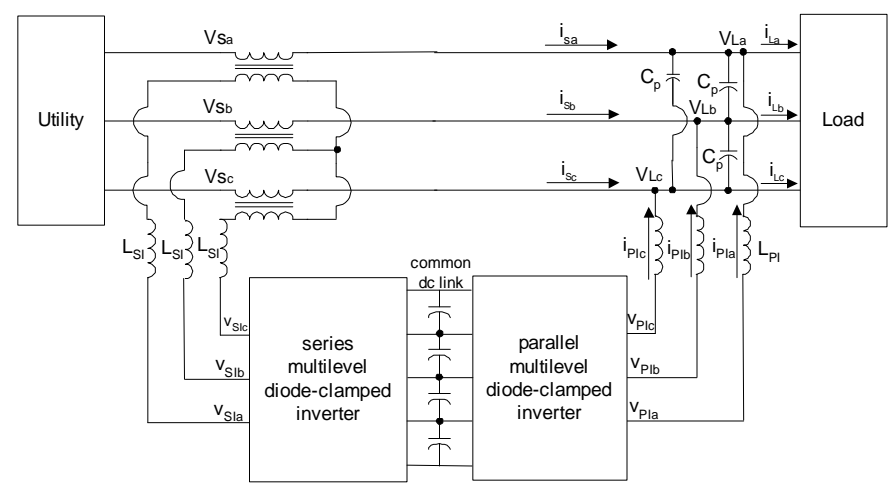

Fig. 1. Series-parallel connection to electrical system of back-to-back multilevel diode clamped inverters for universal power conditioner.

\section{SERIES INVERTER CONTROL}

Fig. 1 shows a block diagram of the two inverters (series and parallel) and the interconnection with the electrical system. For the analysis in this paper, the turns ratio for each of the series transformers was chosen to be 1 . The algorithm used to regulate the load voltage is the short time window sampling technique proposed by Joos and Moran [8]. The load reference voltage, which must be synchronized with the source phase voltages, is generated directly from the sample of two line-line source voltages over a short time frame. This technique requires that the source voltage be close to sinusoidal, which is the case for the majority of electrical installations at the interface between a large industrial customer and a utility.

To determine the phase angle for a sinusoidal synchronizing voltage, $v_{\text {sync }}$, one can make use of the following equations:

$$
\begin{gathered}
\theta_{\text {sync }}=\arctan \left[\frac{v_{s y n c_{k}} \cdot \sin \left(\omega T_{s}\right)}{v_{s y n c_{k}} \cdot \cos \left(\omega T_{s}\right)-v_{s y n c_{k-1}}}\right], \\
\text { where } v_{\text {sync }}=\frac{v_{S a b}-v_{S c a}}{3},
\end{gathered}
$$

and where $v_{s a b}$ and $v_{s c a}$ are source line-line instantaneous samples and $T_{s}$ is the sampling period. For a system with 1024 samples per cycle, $\omega T_{s}=2 \pi / 1024$ radians. By sampling these two line-line voltages, a synchronization signal can be obtained even if one of the phase voltages collapses to zero, as in the case of a single phase to ground solid fault.

The three instantaneous load reference voltages can then be given by the following equations:

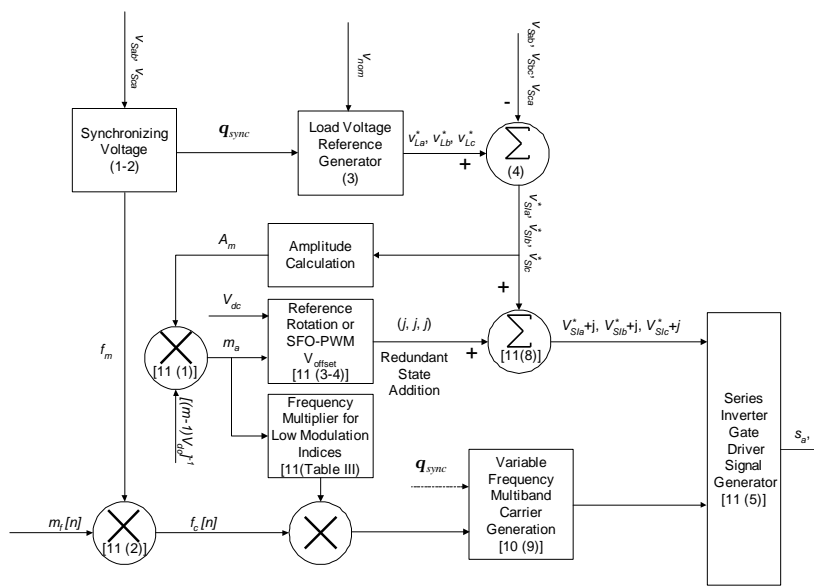

Fig. 2. Serial inverter control block diagram.

$$
\begin{gathered}
v_{L a}^{*}=\frac{V_{n o m}}{\sqrt{3}} \cdot \sin \left(\theta_{\text {sync }}\right), \\
v_{L b}^{*}=\frac{V_{n o m}}{\sqrt{3}} \cdot \sin \left(\theta_{\text {sync }}-\frac{2 \pi}{3}\right), \\
v_{L c}^{*}=\frac{V_{n o m}}{\sqrt{3}} \cdot \sin \left(\theta_{\text {sync }}+\frac{2 \pi}{3}\right),
\end{gathered}
$$

where $V_{\text {nom }}$ is the nominal or desired line-line voltage for the load electrical system. The instantaneous reference signals for the series inverter to compensate for deviations in the source voltage are then equal to the difference between the instantaneous load reference voltages given in (3) and the actual source phase voltages derived from the line-line instantaneous samples:

$$
\begin{aligned}
& v_{S I a}^{*}=v_{L a}^{*}-\left(\frac{v_{S a b}-v_{S c a}}{3}\right), \\
& v_{S I b}^{*}=v_{L b}^{*}-\left(\frac{v_{S b c}-v_{S a b}}{3}\right), \\
& v_{S I c}^{*}=v_{L c}^{*}-\left(\frac{v_{S c a}-v_{S b c}}{3}\right) .
\end{aligned}
$$

These three series inverter reference signals (4) are the modulation waveforms that are compared against a set of triangular carrier waves to determine the switching of the series inverter active devices.

A control structure is shown in block diagram form in Fig. 2. From the serial inverter reference voltages (4), the amplitude modulation index $\left(m_{a}\right)$ is determined. For low modulation indices $\left(m_{a}<0.50\right.$ for all three phases), the 


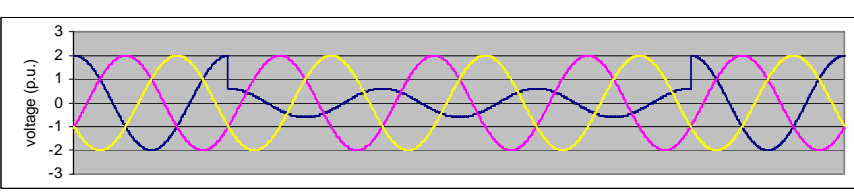

(a) source phase voltages, $v_{S a}, v_{S b}, v_{S c}$

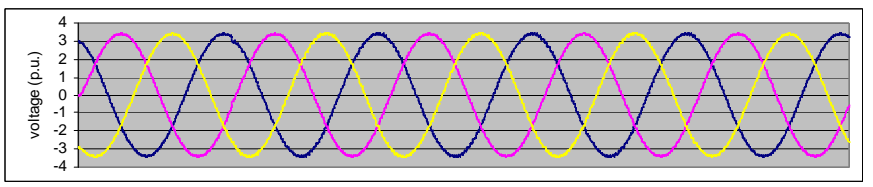

(b) load line-line voltages, $v_{L a b}, v_{L b c}, v_{L c a}$

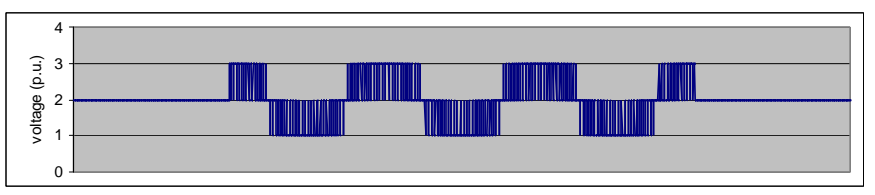

(c) series inverter phase voltage, $v_{S I a}$

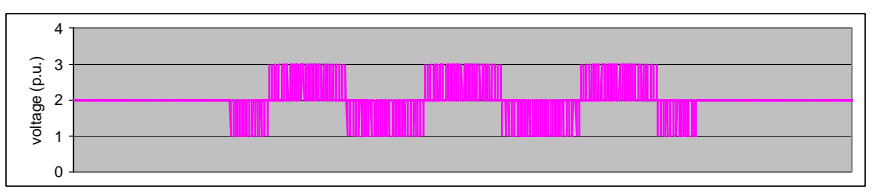

(d) series inverter phase voltage, $v_{S I b}$

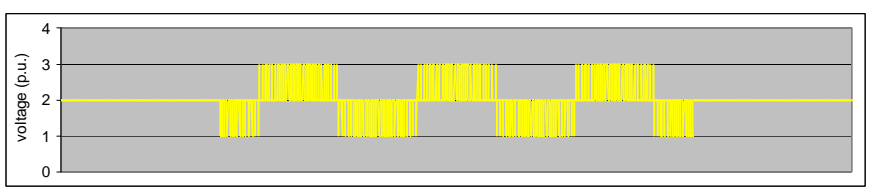

(e) series inverter phase voltage, $v_{S c}$

Fig. 3. System voltage waveforms for single-phase sag $\left(v_{S a}\right)$ to $0.3 \cdot V_{\text {nom }}$.

carrier frequency can be increased, and the reference voltages are rotated among carrier bands as detailed in [11]. For high modulation indices $\left(m_{a}>1.00\right)$, SFO-PWM is implemented as discussed in [10]. The modified reference signals, which may differ from the original reference signals by a triplen addition (SFO-PWM) or redundant state addition (reference rotation), are then compared against the multiband triangular carriers to calculate the switching signals that are the control signals for the active devices.

Computer simulations were used to evaluate the performance of the synchronizing and balancing algorithm under different sag or surge conditions. The amplitude magnitude of the load reference voltage $V_{\text {nom }}$ was chosen to be equal to a 5-level diode-clamped inverter's dc link voltage.

In order to reduce the ripple in the load voltage because of injection of voltage by the series inverter, the low pass filter formed by $L_{S I}$ and $C_{p}$ in Fig. 1 is necessary. For a $60 \mathrm{~Hz}$ electrical system, the optimum cutoff frequency of the filter was found to be $60 \mathrm{~Hz}$. Higher cutoff frequencies of the filter resulted in high ripple content of the load voltage, and lower cutoff frequencies resulted in large phase shifts between the

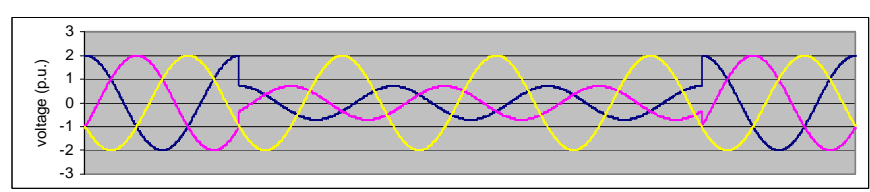

(a) source phase voltages, $v_{S a}, v_{S b}, v_{S c}$

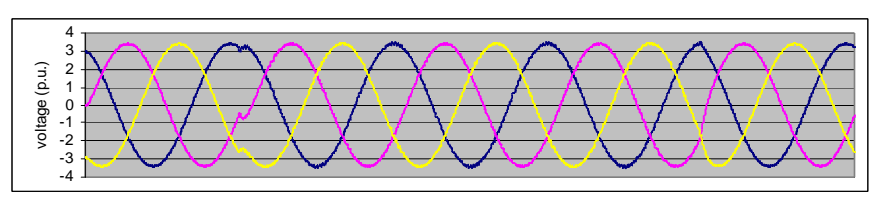

(b) load line-line voltages, $v_{L a b}, v_{L b c}, v_{L c a}$

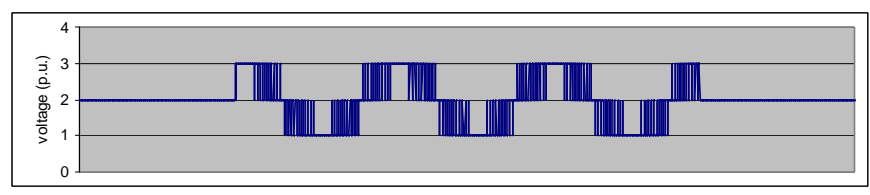

(c) series inverter phase voltage, $v_{\text {SIa }}$

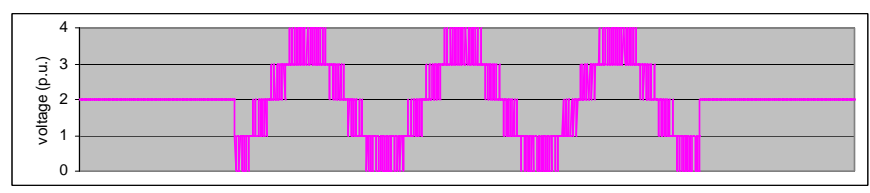

(d) series inverter phase voltage, $v_{S l b}$

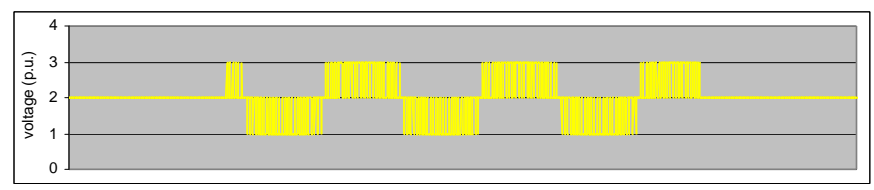

(e) series inverter phase voltage, $v_{S L}$

Fig. 4. System voltage waveforms for two-phase sag $\left(v_{S a}, v_{S b}\right)$ to $0.35 \cdot V_{n o m}$.

source voltage and load voltage and a reduction in the magnitude of the load voltage.

Fig. 3 shows series compensation for a single-phase fault on phase $a$ that decreased its voltage to $0.3 \cdot V_{\text {nom }}$. The inverter compensates immediately and almost instantaneously for this fault such that the load voltage is well regulated and balanced. Even with this severe fault, the reference waveforms for the three phases of the inverter have an amplitude modulation index less than 0.5 (for a transformer turns ratio of 1), and hence only three of the five available levels in the diode-clamped inverter are needed.

As shown in Fig. 3 (c), (d), and (e), the synchronization and voltage regulation algorithm makes use of all three inverter phases to compensate for a sag in just one of the three source voltage phases. This illustrates that this algorithm is applicable to only three-phase, three-wire systems and not to three-phase, four-wire systems. For the example represented in Fig. 3, rotation of the reference waveform among different carrier band sets is possible as discussed in [11]. A singlephase fault that reduces the source voltage to less than 


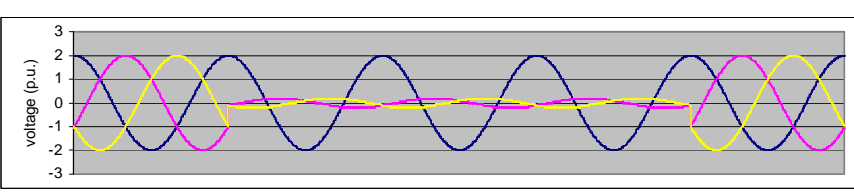

(a) source phase voltages, $v_{S a}, v_{S b}, v_{S c}$

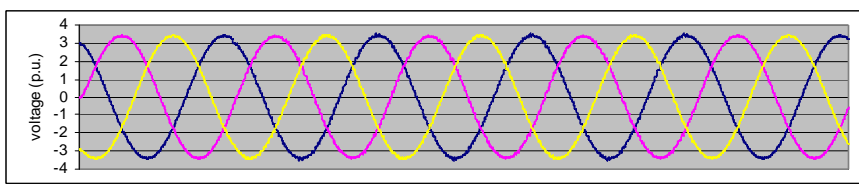

(b) load line-line voltages, $v_{L a b}, v_{L b c}, v_{L c a}$

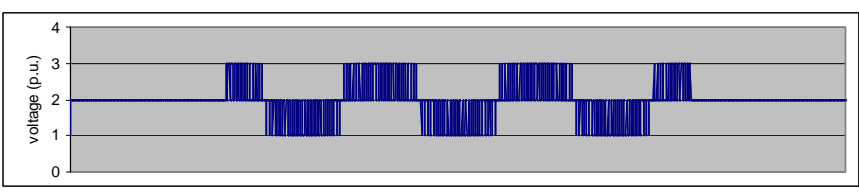

(c) series inverter phase voltage, $v_{S I a}$

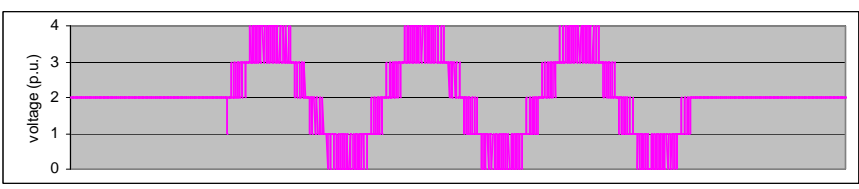

(d) series inverter phase voltage, $v_{S I b}$

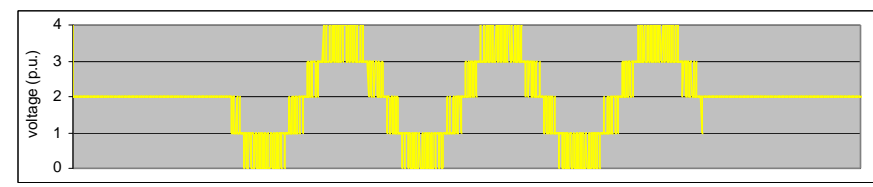

(e) series inverter phase voltage, $v_{S c}$

Fig. 5. System voltage waveforms for two-phase sag $\left(v_{S b}, v_{S c}\right)$ to $0.10 \cdot V_{n o m}$.

$0.25 \cdot V_{\text {nom }}$ is necessary before use of all five levels in one phase of the diode-clamped inverter is required.

For the algorithm defined by (1) and (2), a significant double phase fault that involves phase $a$ results in a phase shift between the load voltage and source voltage at the initiation and conclusion of compensation by the series inverter. Fig. 4 represents the case where phases $a$ and $b$ have a double-phase fault to ground that causes the source voltage to dip by $65 \%$ to $0.35 \cdot V_{\text {nom }}$. The phase shift in the load voltages can be seen at the beginning and end of the fault. For this particular example, the phase shift introduced was $22.5^{\circ}$. The worst case would be when two phases are completely grounded, and the resultant phase shift is $60.8^{\circ}$ in the phase voltage at the beginning and ending of voltage compensation.

Because phase $a$ is the reference for the other two phases in the synchronization algorithm, simulations have shown that if phase $a$ is not involved in the fault, however, no substantial phase shift is introduced in the load voltages. Fig. 5 shows the case where phases $b$ and $c$ of the source voltage have been

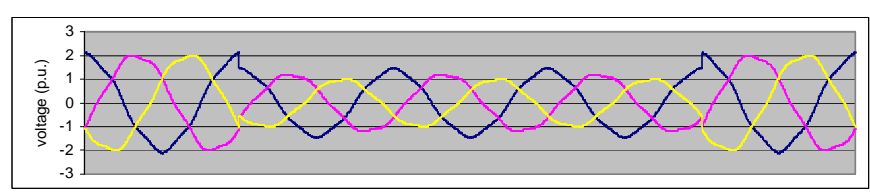

(a) source phase voltages, $v_{S a}, v_{S b}, v_{S c}$

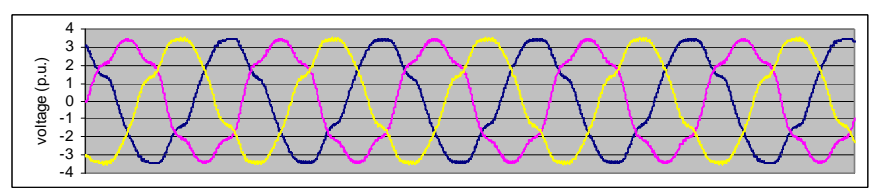

(b) load line-line voltages, $v_{L a b}, v_{L b c}, v_{L c a}$

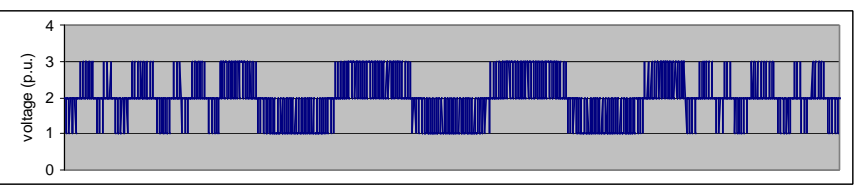

(c) series inverter phase voltage, $v_{S l a}$

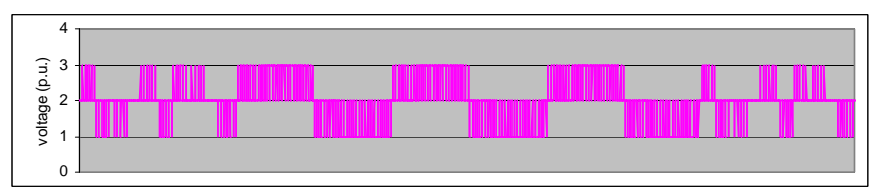

(d) series inverter phase voltage, $v_{S l b}$

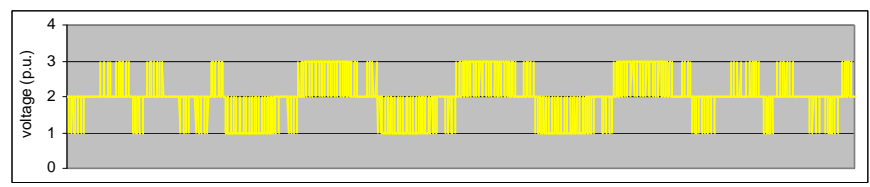

(e) series inverter phase voltage, $v_{S l c}$

Fig. 6. System voltage waveforms for three-phase unbalanced sag when source voltage has $5 \% 5^{\text {th }}$ harmonic distortion.

reduced to $0.1 \cdot V_{\text {nom }}$ by a severe sag. As shown in Fig. 5 , the load voltages are well regulated, even for this extreme case. A double-line to ground fault that reduces the source voltage to less than $0.53 \cdot V_{\text {nom }}$ is necessary before all five levels of the diode-clamped inverter are needed. A less severe fault will result in only three levels being used and reference rotation being possible [11].

The drawback of the synchronizing and balancing algorithm is that it cannot compensate for voltage harmonics because it was derived for sinusoidal source voltages. The algorithm does function for small distortions in the source voltage (generally less than 5\% total harmonic distortion), but the load voltage will have about the same harmonic content as the source voltage. Fig. 6 represents three source voltages that have a $5 \% 5^{\text {th }}$ harmonic sequence and experience a threephase unbalanced sag for a three-cycle duration. The load voltage is balanced and well regulated, but it has about the same distortion as the source voltage.

Another drawback of the algorithm is that hardware implementation is difficult because of the precision needed 


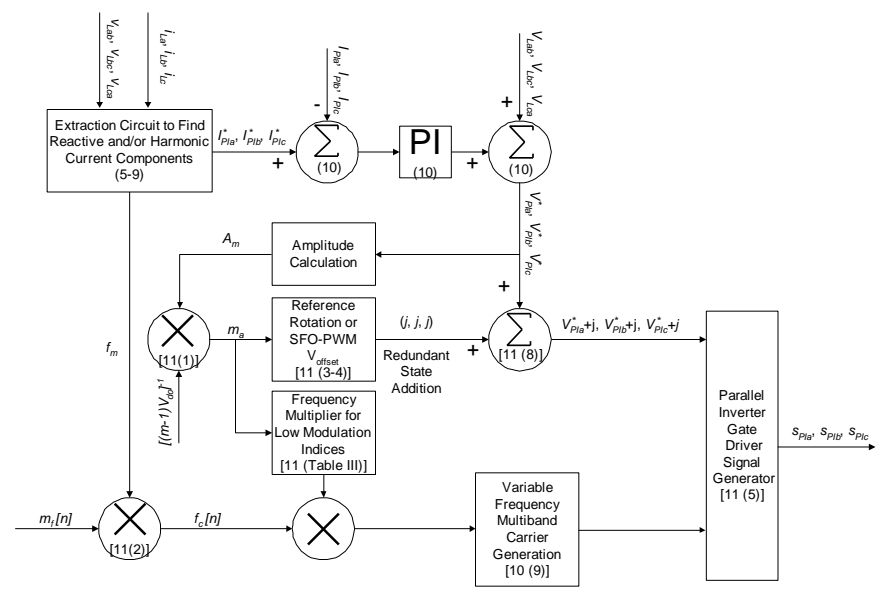

Fig. 7. Parallel inverter control block diagram.

for the calculation of the denominator of (1). The analog to digital conversion for most digital signal processors will not have the required precision for a sampling rate of 1024 samples/cycle. Execution time of the processor is also a concern when calculating (1) because of the arctan term.

\section{PARALlEl INVERTER CONTROL}

The parallel inverter is responsible for supplying the reactive and/or harmonic current demanded by the load. Generalized instantaneous power theory, as outlined by Peng in [9], is used for the control of the parallel inverter. This theory works well for balanced voltages, which should be the case for the load voltages because of the series compensation of the source voltage. For the case where unbalanced voltages were present, the instantaneous power theory where the currents are chosen to follow the voltage waveform is more appropriate [12]. A control structure is shown in block diagram form in Fig. 7.

Using instantaneous power theory (generalized $p q$-theory), the instantaneous reference current for the parallel compensation control is given by the following vector equation:

$$
\vec{i}_{P I}^{*}=\frac{p_{c}^{*} \vec{v}_{L}}{\vec{v}_{L} \cdot \vec{v}_{L}}+\frac{\vec{q}_{c}^{*} \times \vec{v}_{L}}{\vec{v}_{L} \cdot \vec{v}_{L}}
$$

where $p_{c}{ }^{*}$ and $q_{c}{ }^{*}$ are extracted from the active and reactive power of the load, $p_{L}$ and $q_{L}$, which are given as follows:

$$
\begin{gathered}
p_{L}=\vec{v}_{L} \cdot \vec{i}_{L}=v_{L a} \cdot i_{L a}+v_{L b} \cdot i_{L b}+v_{L c} \cdot i_{L c} ; \\
\vec{q}_{L}=\vec{v}_{L} \times \vec{i}_{L},
\end{gathered}
$$

$$
\begin{gathered}
\text { or } q_{L a}=v_{L b} \cdot i_{L c}-v_{L c} \cdot i_{L b}, \\
q_{L b}=v_{L c} \cdot i_{L a}-v_{L a} \cdot i_{L c}, \\
\text { and } q_{L c}=v_{L a} \cdot i_{L b}-v_{L b} \cdot i_{L a} .
\end{gathered}
$$

For the compensation objective of making the source current unity power factor (and sinusoidal for a source voltage with little distortion), $q_{c}{ }^{*}$ is set equal to $q_{L}$ and $p_{c}{ }^{*}$ is set equal to the load ripple active power $p_{\iota}$, where

$$
\tilde{p}_{L}=p_{L}-\bar{p}_{L},
$$

and where $\bar{p}_{L}$ is the dc component of the load active power.

A low pass filter is necessary for extraction of the dc component from the load active power. A digital low pass filter was implemented as follows:

$$
\bar{p}_{L_{k}}=\left(\frac{T_{c}}{T_{s}+T_{c}}\right) \cdot \bar{p}_{L_{k-1}}+\left(\frac{T_{s}}{T_{s}+T_{c}}\right) \cdot p_{L_{k}},
$$

where $T_{c}$ is the inverse of the filter's cutoff frequency $f_{c}$. For a sampling frequency of 1024 times per cycle and a $60 \mathrm{~Hz}$ electrical system, the optimum cutoff frequency of the low pass filter was found to be $5 \mathrm{~Hz}$. Simulation results showed that with a lower cutoff frequency of the low pass filter, more of the active power ripple is filtered but at the expense of an extended response time to step changes in the load current. Higher cutoff frequencies resulted in better response times but at the expense of filtering less of the active power ripple. With the $5 \mathrm{~Hz}$ cutoff frequency, the response time to a step change was approximately 1.5 cycles and generally better than $90 \%$ of the active power ripple was filtered.

The parallel inverter of the MUPC injects currents by impressing a voltage across the parallel inductors, $L_{P I}$, that is the difference between the load voltage $V_{L}$ and output voltage $V_{P I}$. The parallel inverter has to provide a voltage $V_{P I}$ * such that the inverter supplies a current that tracks the current reference computed in (5). This voltage was computed from the following vector equation:

$$
\vec{v}_{P I}^{*}=\vec{v}_{L}+\left(\vec{i}_{P I}^{*}-\vec{i}_{P I}\right) \cdot \frac{L_{p}}{\omega T_{s}} .
$$

Again from simulation, an impedance of the parallel inductance of $40 \cdot \omega T_{s}$ ohms yielded a current that tracked the reference current well. Smaller values resulted in compensation currents with a high ripple content, and for larger values, the tracking of the reference current was too slow to eliminate the distortion present in the load current.

Simulation results showed that the amplitude of the desired load voltage $V_{\text {nom }}$ should not be more than $70 \%$ of the overall 
dc link voltage for the MUPC to be able to impress enough voltage across the parallel inductance to compensate for reactive currents when the load voltage is at its maximum or minimum amplitude. Without this margin, complete compensation of reactive currents may not be possible.

Fig. 8 shows waveforms for an electrical system with current compensation where the load current had a $20 \% 7^{\text {th }}$ harmonic component and a 0.7 displacement power factor. The source current immediately becomes sinusoidal and in phase with the source phase voltages once compensation by the MUPC has begun. The parallel inverter supplies a substantial reactive current to compensate for the large reactive power drawn by the load.

The filter described by (9) does not completely filter the ripple in the load power for severely unbalanced conditions. Fig. 9 shows what the source voltage, load current, and source current look like for compensation of the load current under unbalanced current conditions $\left(i_{L b}=-i_{L a}, i_{L c}=0\right)$.

Fig. 10 shows some waveforms from an MUPC system with an ideal low-pass filter with the same load current example as used in Fig. 9. The currents are now almost completely distortion-free as shown in Fig. 10(b), and the ripple in the real power transmitted to the load has been eliminated as shown in Fig. 10(f).

\section{CONCLusions}

In this paper, a real-time control scheme was developed for a complete multilevel universal power conditioner system. Because of the different compensation objectives of the series inverter and parallel inverter, two distinct techniques were adapted for use by the two converters.

The short time window sampling technique employed for use with the series inverter enabled regulation of the load voltage under unbalanced fault conditions with the assumption that the source voltage is fairly sinusoidal. Simulation results showed that only for a severe fault would all of the levels in a MUPC be required for compensation. For the majority of the sags experienced on an electrical system, only part of the voltage levels in a MUPC are used. Under these conditions, the rotation of level usage as described in [11] is an effective means of balancing level usage and in some cases increasing possible switching frequency.

The generalized pq-method was used for load current compensation by the parallel inverter. This method minimized the currents drawn from the utility by eliminating all of the reactive power and the ripple in the real power transferred to the load.

Because the parallel inverter of the MUPC injects currents by impressing a voltage across an inductance with respect to the load voltage, in most cases all of the voltage levels in the parallel inverter are used. In addition, the desired load voltage $V_{\text {nom }}$ should not be more than $70 \%$ of the dc link

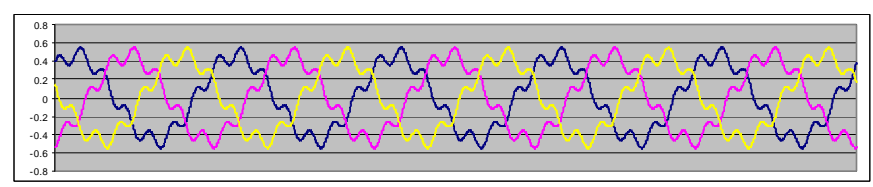

(a) load currents, $i_{L a}, i_{L b}, i_{L c}$

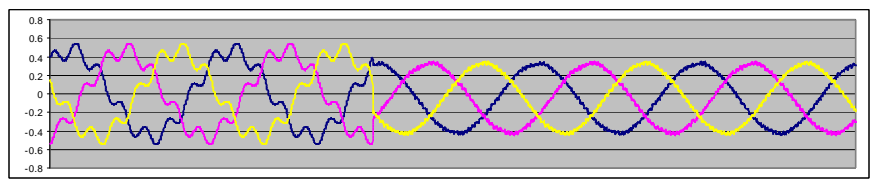

(b) source currents, $i_{S a}, i_{s b}, i_{S c}$

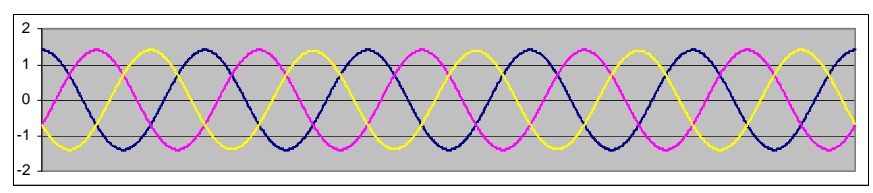

(c) source phase voltages, $v_{S a}, v_{S b}, v_{S c}$

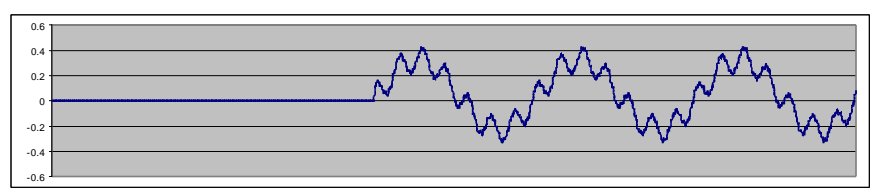

(d) parallel inverter current for phase $a, i_{\text {Pla }}$

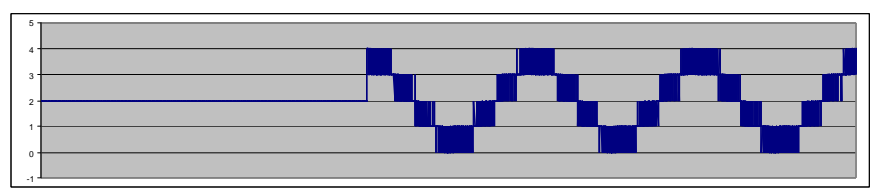

(e) parallel inverter phase voltage, $v_{P l a}$

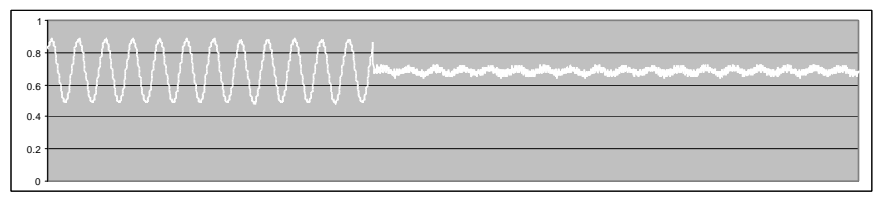

(f) load real power, $p_{L}$

Fig. 8. System waveforms for current compensation with load current that has $20 \% 7 \mathrm{th}$ h armonic component and a displacement power factor of 0.7 .

voltage, so that the MUPC can still impress the proper voltage across the parallel inductance when the load voltage is at its maximum or minimum amplitude.

\section{REFERENCES}

[1] H. Fujita, H. Akagi, “The Unified Power Quality Conditioner: The Integration of Series- and Shunt-Active Filters," IEEE Transactions on Power Electronics, vol. 13, no. 2, March 1998, pp. 315-322.

[2] S.-J. Jeon, G.-H. Cho, “A Series-Parallel Compensated Uninterruptible Power Supply with Sinusoidal Input Current and Sinusoidal Output Voltage," IEEE Power Electronics Specialists Conference, 1997, pp. 297-303.

[3] F. Kamran, T. G. Habetler, "Combined Deadbeat Control of a SeriesParallel Converter Combination Used as a Universal Power Filter," IEEE Transactions on Power Electronics, vol. 13, no. 1, Jan. 1998, pp. 160168. 


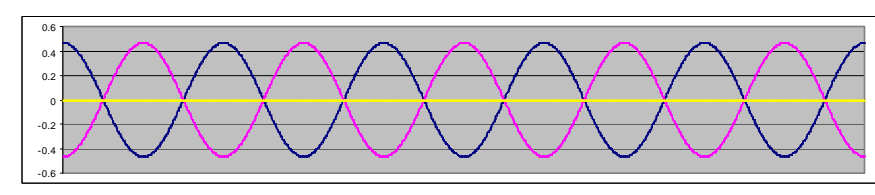

(a) load currents, $i_{L a}, i_{L b}, i_{L c}$

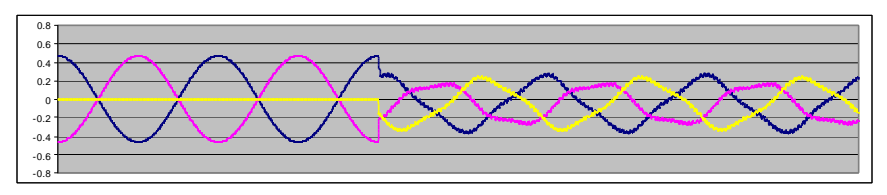

(b) source currents, $i_{S a}, i_{S b}, i_{S c}$

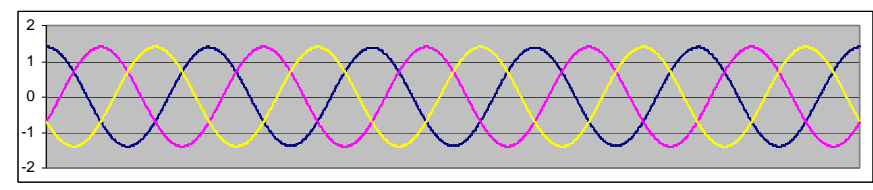

(c) source phase voltages, $v_{S a}, v_{S b}, v_{S c}$

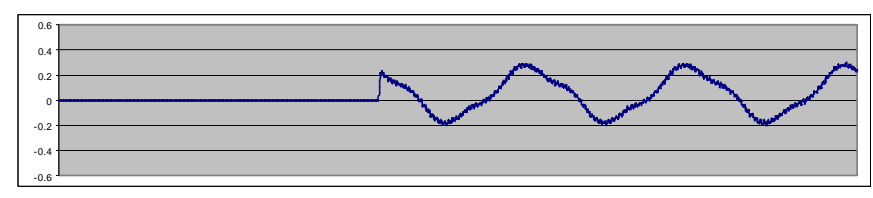

(d) parallel inverter current for phase $a, i_{P l}$

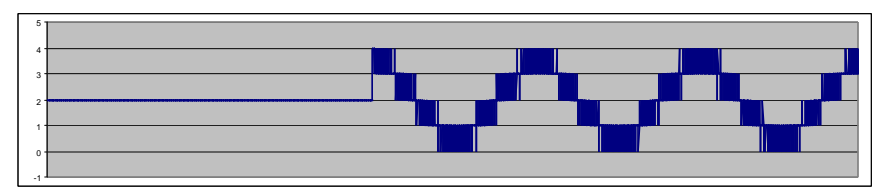

(e) parallel inverter phase voltage, $v_{P I a}$

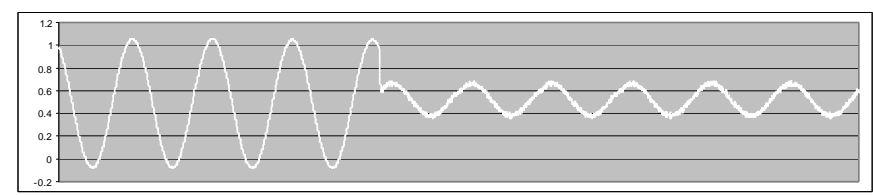

(f) load real power, $p_{L}$

Fig. 9. System waveforms for current compensation under unbalanced current conditions $\left(i_{L b}=-i_{L a}, i_{L c}=0\right)$ using the filter described by (9).

[4] B. Mwinyiwiwa, B.-T. Ooi, Z. Wolanski, "Multimodular UPFC Operated by Phase-Shifted Triangle Carrier SPWM Strategy," Conference Record - IEEE Industry Applications Society Annual Meeting, 1997, pp. 1641-1646.

[5] Y. Chen, B. Mwinyiwiwa, Z. Wolanski, B.-T. Ooi, "Unified Power Flow Controller (UPFC) Based on Chopper Stabilized Multilevel Converter," IEEE Power Electronics Specialists Conference, 1997, pp. 331-337.

[6] L. Gyugi, et. al., "The Unified Power Flow Controller: A New Approach to Power Transmission Control," IEEE Transactions on Power Delivery, vol. 10, no. 2, April 1995, pp. 1085-1093.

[7] J. S. Lai, F. Z. Peng, "Multilevel Converters - A New Breed of Power Converters," IEEE Transactions on Industry Applications, vol. 32, no. 3, May 1996, pp. 509-517.

[8] G. Joos, L. Moran, "Principles of Active Power Filters," IEEE - IAS'98 Tutorial Course Notes, St. Louis, Missouri, October 1998.

[9] F. Z. Peng, G. W. Ott, Jr., D. J. Adams, "Harmonic and Reactive Power Compensation Based on the Generalized Instantaneous Reactive Power

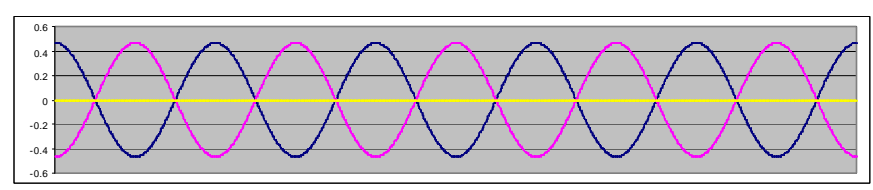

(a) load currents, $i_{L a}, i_{L b}, i_{L c}$

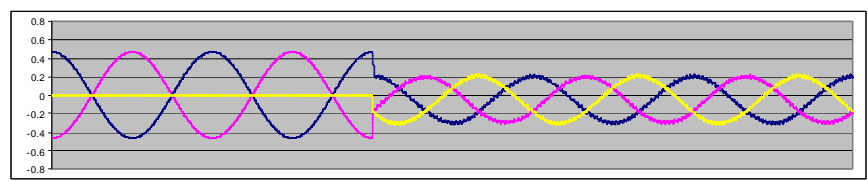

(b) source currents, $i_{S a}, i_{S b}, i_{S c}$

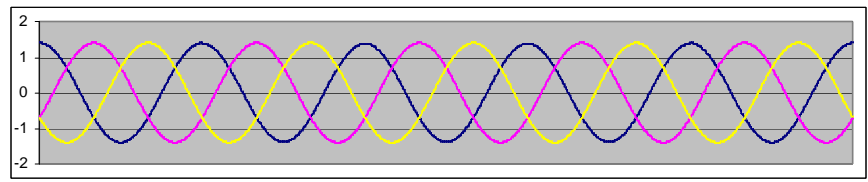

(c) source phase voltages, $v_{S a}, v_{S b}, v_{s c}$

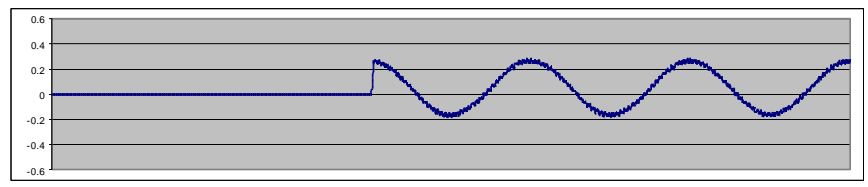

(d) parallel inverter current for phase $a, i_{P i a}$

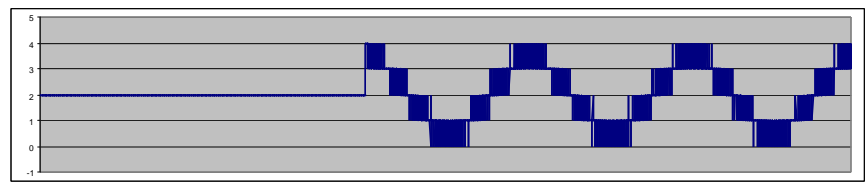

(e) parallel inverter phase voltage, $v_{P I a}$

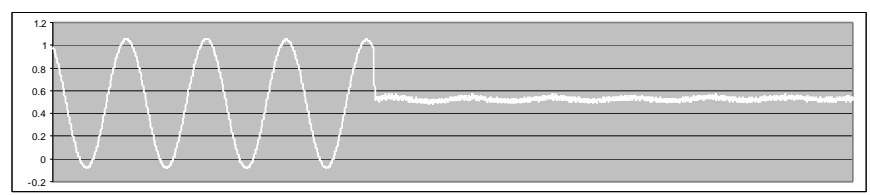

(f) load real power, $p_{L}$

Fig. 10. System waveforms for current compensation for unbalanced current conditions $\left(i_{L b}=-i_{L a}, i_{L c}=0\right)$ using an ideal low-pass active filter.

Theory for Three-Phase Four-Wire Systems," IEEE Transactions on Power Electronics, vol. 13, no. 6, Nov. 1998, pp. 1174-1181.

[10] L. M. Tolbert, T. G. Habetler, "Novel Multilevel Inverter Carried-Based PWM Methods," Conference Record - IEEE Industry Applications Society Annual Meeting, 1998, pp. 1424-1431.

[11] L. M. Tolbert, F. Z. Peng, T. G. Habetler, "Multilevel Carrier-Based PWM Methods at Low Modulation Indices," IEEE Applied Power Electronics Conference, 1999, pp. 1032-1039.

[12] L. Rossetto, P. Tenti, "Evaluation of Instantaneous Power Terms in Multi-Phase Systems: Techniques and Applications to PowerConditioning Equipment," ETEP, vol. 4, Nov. 1994, pp. 469-475. 